\title{
A new environmental monitoring system for silkworm
}

\section{incubators [version 1; peer review: 1 approved, 1 approved}

\section{with reservations]}

\section{Alejandra Duque-Torres (D1, Carlos Rodriguez-Pabon1, Juan Ruiz-Rosero1, Giselle Zambrano-Gonzalez (D)2, Martha Almanza-Pinzon³, Oscar Mauricio Caicedo Rendon (D1, Gustavo Ramirez-Gonzalez (Di)1}

\footnotetext{
${ }^{1}$ Telematic Engineering Department, Telematic Engineering Research Group (GIT), University of Cauca, Popayán, Cauca, 190002, Colombia

2Biology Department, Geology, Ecology and Conservation Research Group (GECO), University of Cauca, Popayán, Cauca, 190002, Colombia

${ }^{3}$ Agropecuary Sciences Department, Production Integrated Systems Research Group (SISINPRO), University of Cauca, Popayán, Cauca, 190002, Colombia
}

V1 First published: 28 Feb 2018, 7:248

https://doi.org/10.12688/f1000research.13633.1

Latest published: 28 Feb 2018, 7:248

https://doi.org/10.12688/f1000research.13633.1

\section{Abstract}

Silk is known as the queen of textiles due to its softness, durability, and luster. This textile is obtained from cocoons spun by larvae known as the silkworm. The combined effect of both temperature and humidity, determines the satisfactory growth of the silkworms and the production of good quality cocoons. For that rea- son, we propose a new prototype for silkworm incubators that monitors environmental conditions, created with Raspberry Pi due to its capabilities, features, and low cost. The prototype monitors the temperature, humidity, and luminosity in a silkworm incubator. The monitoring data are collected and saved on file hosting service, Google Drive, for subsequent analysis. Preliminary tests were gathered using the silkworm incubator of University of Cauca, Colombia.

\section{Keywords}

silkworm incubator, environmental conditions, monitoring, Raspberry$\mathrm{Pi}$, cloud

\section{Open Peer Review}

\begin{tabular}{ccc} 
Approval Status & $?$ \\
\hline & 1 & 2 \\
\hline version 1 & $?$ & \\
28 Feb 2018 & view & view \\
\hline
\end{tabular}

1. Enrico Petritoli, Roma Tre University, Rome, Italy

Fabio Leccese (ID), Roma Tre University, Rome, Italy

\section{LalBihari Barik (iD), King Abdulaziz}

University, Rabigh, Saudi Arabia

Any reports and responses or comments on the article can be found at the end of the article. 
Corresponding authors: Alejandra Duque-Torres (aduquet@unicauca.edu.co), Carlos Rodriguez-Pabon (davidrodriguez298@gmail.com ), Juan Ruiz-Rosero (jpabloruiz@unicauca.edu.co), Giselle Zambrano-Gonzalez (gzambranog@unicauca.edu.co), Martha Almanza-Pinzon ( malmanza@unicauca.edu.co), Oscar Mauricio Caicedo Rendon (omcaicedo@unicauca.edu.co), Gustavo Ramirez-Gonzalez ( gramirez@unicauca.edu.co)

Author roles: Duque-Torres A: Methodology, Writing - Original Draft Preparation; Rodriguez-Pabon C: Methodology, Writing - Original Draft Preparation; Ruiz-Rosero J: Formal Analysis, Resources, Writing - Review \& Editing; Zambrano-Gonzalez G: Formal Analysis, Resources, Writing - Review \& Editing; Almanza-Pinzon M: Writing - Review \& Editing; Caicedo Rendon OM: Writing - Review \& Editing; Ramirez-Gonzalez G: Formal Analysis, Project Administration, Resources, Writing - Review \& Editing

Competing interests: No competing interests were disclosed.

Grant information: This research is funded by Colciencias Doctoral scholarship 647-2014 for the PhD in Telematic Engineering at the Universidad del Cauca, Popayán, Colombia. The purchase of the materials was made with resources provided by the National Ph.D. Scholarship for Teachers granted by the Human Talent Training Network Project for Social and Productive Innovation in the Department of Cauca - InnovAcción Cauca.

The funders had no role in study design, data collection and analysis, decision to publish, or preparation of the manuscript.

Copyright: @ 2018 Duque-Torres A et al. This is an open access article distributed under the terms of the Creative Commons Attribution License, which permits unrestricted use, distribution, and reproduction in any medium, provided the original work is properly cited.

How to cite this article: Duque-Torres A, Rodriguez-Pabon C, Ruiz-Rosero J et al. A new environmental monitoring system for silkworm incubators [version 1; peer review: 1 approved, 1 approved with reservations] F1000Research 2018, 7:248 https://doi.org/10.12688/f1000research.13633.1

First published: 28 Feb 2018, 7:248 https://doi.org/10.12688/f1000research.13633.1 


\section{Introduction}

Silk is known as the queen of textiles due to its softness, durability, and luster. Furthermore, the silk fibers provide characteristics that are superior to any other type of fiber (e.g., water absorbency, heat resistance, dyeing efficiency, and luster). This textile is obtained from cocoons spun by larvae known as silkworm (Bombyx mori), which were discovered in China between 2600 and $2700 \mathrm{BC}$. The process of silk production is known as sericulture, beginning with the rearing of the silkworm ${ }^{1}$.

The silkworm is of great interest to the sericulture industry and the academic community. Because of this, there is an increased interest in knowing the combination of factors that affect growth and development of silkworms in different life stages, which in turn affects productivity, and quality of silk $^{2}$.

The insects can only survive in specific conditions, defined by environmental factors such as temperature, relative humidity, or duration light. These environmental factors directly affect different activities such as feeding, dispersal, laying or development. Temperature is probably the environmental factor that exerts the most significant effect on the development of the insects ${ }^{3}$.

It is well known that the silkworm is highly sensitive to environmental variation ${ }^{1,2,4-6}$. Indeed, in an extreme natural fluctuation, it could be unable to survive because of its extended period of domestication, of about 5000 years $^{5}$. The biological as well as physiology-related, characteristics (e.g., growth, development, productivity, and quality of silk), are influenced by the combination of temperature, air circulation, humidity, light duration, and gases.

The study of the effects of varying environmental conditions, will generate essential biological information that will allow production of cocoons in areas where the silkworm is of economic value.

Recent progress in electronics, wireless communications, and production of small size sensors provides new opportunities to develop different monitoring systems (e.g., for homes, crops and the environment) ${ }^{7}$. A sensor is a device that can measure physical attributes and convert them into signals for the user. Sensors are the essential components of the environmental monitoring system of this proposal in addition to the embedded systems ${ }^{8}$.

To monitor the environmental conditions during the silkworm incubation and rearing process, we proposed an environmental conditions monitoring system that makes full use the concept of an open source and low-cost data acquisition and transmission system. We used an embedded platform, with cloud remote monitoring through the file hosting service Google drive, and the Internet of Things.

We describe the prototype for monitoring temperature, humidity relative, and light intensity in a silkworm incubator. Also, we provide the required tools for reproducibility of the system.

In the following sections, we describe a silkworm incubator, the materials used, prototype design, and results obtained. We also discuss the results and the possibility of future work around this topic.

\section{Methods}

\section{System monitoring overview}

Figure 1 shows the proposed conceptual model of the monitoring system. There are three main stages: the reading of sensors, the communication channel, and storage of data in the cloud. The system is scalable and it is possible to include other sensors and communication technologies. It consists of several sensors that record environmental parameters such as moisture, temperature, and luminosity in a silkworm incubator. The information is then uploaded to the cloud by Google Drive. We used two different sensors to collect data on temperature, humidity, and luminosity. Wi-Fi communication was used to upload the information to Google Drive. Users obtain information about the data recorded with a username and password through a smartphone or any device that supports the Google Drive application.

\section{Silkworm incubator}

The silkworm incubator structure keeps the environment in uniform conditions for temperature and humidity (see Figure 2 and Figure 3). These are the most important variables to control. The water tank is located at the bottom, with a capacity for eight

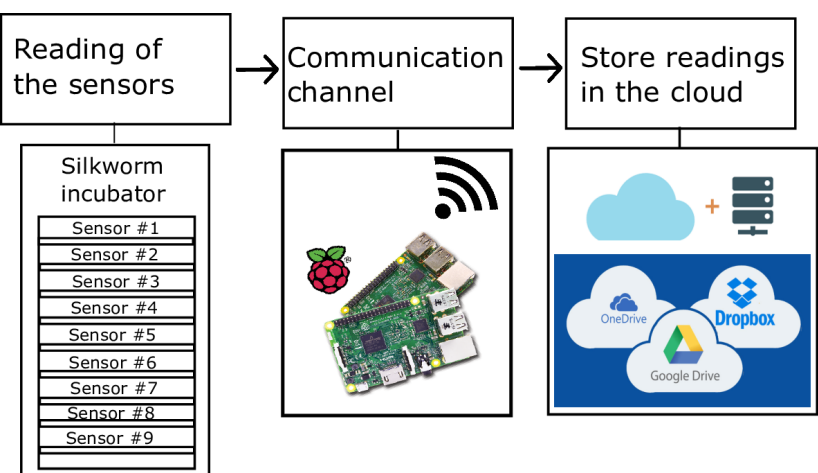

Figure 1. Silkworm incubator monitoring system conceptual model.

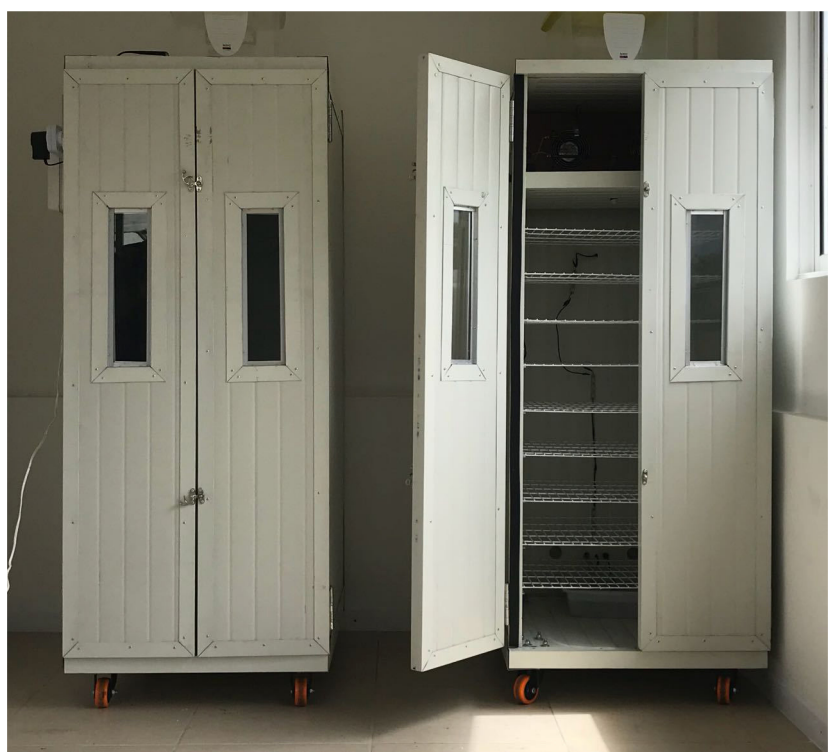

Figure 2. Silkworm incubator, front on view. 
liters of water. The incubation chamber has nine metal mesh trays to allow air flow. The incubator brand is Incubapremium, manufactured in Colombia by Abraham Reyes Sanclemente incubation equipment specialist with 30 years' experience.

Silkworms are distributed in trays that are about one meter wide and $60 \mathrm{~cm}$ long, which facilitates their handling. The materials used for their construction are aluminum and thermal insulation. The trays are placed to form shelves called swaths. Each tray, of the nine that make up the shelves, is separated by approximately $15 \mathrm{~cm}$. The temperature inside the chamber is controlled by a heating system based on an electrical resistance. The humidity is controlled by a humidifier located at the bottom side of the chamber.

\section{Temperature and humidity regulation}

Temperature and humidity plays a vital role in the rearing of the silkworms. As silkworms are cold-blooded animals, the temperature will have a direct effect on various physiological activities $^{1}$. Humidity's role in silkworm rearing is both direct and indirect ${ }^{5}$. The combined effect, of both temperature and humidity, largely determines the satisfactory growth of the silkworms and production of good-quality cocoons. It directly influences the silkworm's physiological functions. The selected sensor was DHT22, which is an essential temperature and humidity digital low-cost sensing device. This sensor has the capability to obtain new data every 2 seconds.

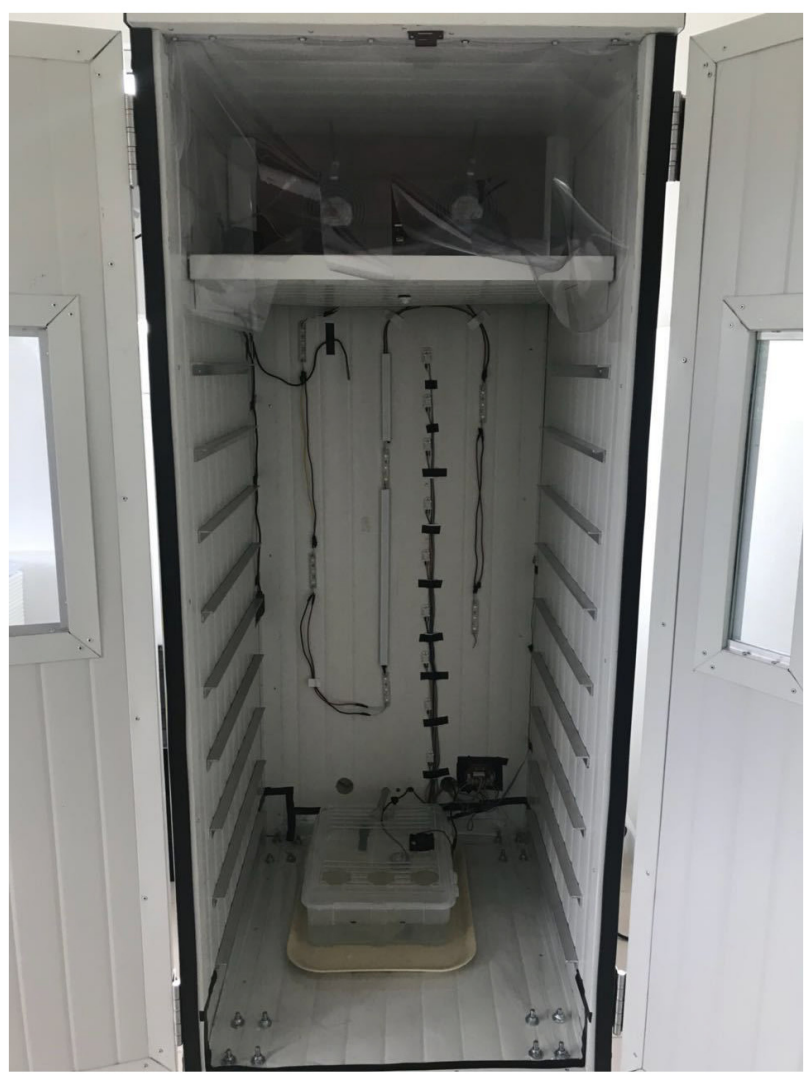

Figure 3. Silkworm incubator, inside view.
Luminosity regulation

Silkworms, like other animals, are photosensitive and tend to crawl into dim light. They do not like strong light or complete darkness ${ }^{1,9-11}$. The breeding of silkworms in continuous light slows down growth and reduces both the weight of the larvae and the cocoon. We choose the luminosity sensor APDS-9301 due to the high precision in measurement and its low power consumption.

\section{Embedded platform}

Raspberry Pi version 3 (RPi3) was chosen for this project, due to its small size and low cost, compared to conventional PC and data loggers, plus zero cost of free Linux software ${ }^{11}$.

RPi3, in comparison to most of the other Linux-based embedded systems, such as Arduino Due, Beagle Bone Black, and Intel Edison, has a better cost-benefit ratio, broader user community, and a more standard programming language and communication, many input-output pins and a graphics interface ${ }^{12}$. A picture of the RPi3 is shown in Figure 4.

\section{Hardware and software development}

The prototype hardware consisted of an RPi3 board inside a plastic box, nine sensors to measure temperature and humidity, and one luminosity sensor. The plastic box was used to protect the RPi3. All of the sensors were placed inside of the silkworm incubator. As aforementioned, the silkworm incubator has nine levels. Therefore, one temperature and humidity sensor was placed in each level and the luminosity sensor was placed in the incubator middle. In the initial design of the monitoring system, we considered necessary only a single light sensor due to the uniform light conditions for all levels.

The monitoring system was developed in three phases: the design of monitoring system architecture, hardware and software requirements, and the implementation.

All the hardware documentation such as schematics of circuits, types of sensor and material specifications used are available in GitHub, along with the documentation of the software developed, such as the communication algorithms between sensor and RP3, the storage algorithm, and the communication algorithm between RP3 and Google Drive service. Furthermore,

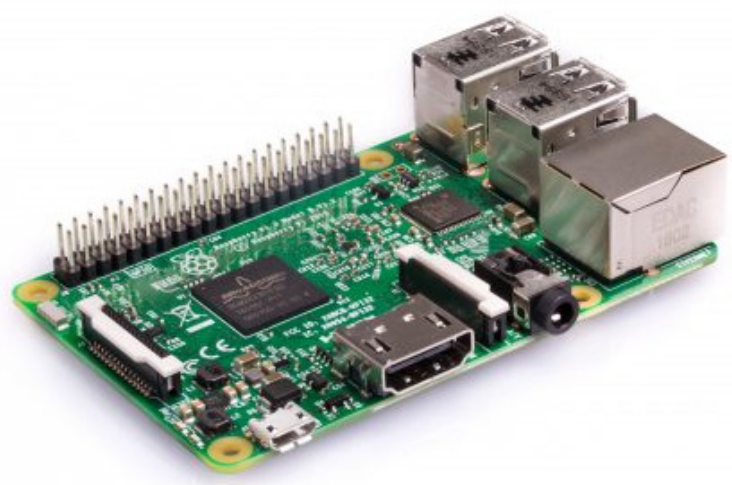

Figure 4. Raspberry pi version 3 board used to develop the monitoring system. 
instructions to install the different libraries necessary for the monitoring system are also contained here.

Architecture of the monitoring system. In the architectures of monitoring systems sensors, data gathering can vary, including data transmission (wired or wireless technologies), data storage and usage of intermediate devices. A particular monitoring system can also be supplemented with decision support system, which is responsible for data analysis, incubator environment condition determination and appropriate decision selection.

In our monitoring system, by the usage of RP3 the data from sensors using wired communication is transferred and uploaded to the cloud by Google Drive for further analysis (see Figure 5).

Hardware and software requirements. The hardware requirements are the materials aforementioned and the various sensors. The RP3 works with an SD card. It should work with any compatible SD card, although there are some guidelines that we followed from the official documentation for the Raspberry Pi, written by the Raspberry Pi Foundation with community.

The software requirements for the monitoring system are the installations of: the operative system for RP3, the library of the temperature and humidity sensors on RP3, the library of the light sensor, and the Google Drive on RP3. Furthermore, it is necessary to choose the programming language to use; we used Python language. However, other programming laugages can also be used, such as Ruby or $\mathrm{C} / \mathrm{C}++$. The instructions for installing all the cable in the GitHub repository as follows:

1. Operative system for RP3: https://www.raspberrypi.org/ documentation/installation/noobs.md

2. Library for temperature and humidity sensor: https:// github.com/Silkwormincubator/SilkWorm/wiki/ Instructions-for-installing-the-DHT22-libraries-inRaspberry-pi-3

3. Library for light sensor: https://github.com/ Silkwormincubator/SilkWorm/wiki/Installation--Lightsensor-apds 9301
4. Google Drive for RP3: https://github.com/ Silkwormincubator/SilkWorm/wiki/Installation-Google-Drive

The main algorithm of the monitoring system works by initializing the sensors variables to zero; there is a query time where it collects sensor data. The program asks for the time elapsed and if the time elapsed is less to 5 minutes, the system accumulates the sensor values. When the time lapsed exceeds 5 minutes, the program calculates the average of collected sensors values (temperature, humidity, and light) and updates a txt file, which is synchronized with the file on Google Drive. The algorithm for this is available on our GitHub repository.

\section{Field test}

For a field test, worms were obtained through resources provided by the National Ph.D. Scholarship for Teachers granted by the Human Talent Training Network Project for Social and Productive Innovation in the Department of Cauca - InnovAcción Cauca. The monitoring system was used in one incubator. The condition environments of 200 worms was monitored for 25 days continuously.

\section{Results}

As mentioned previously, the aim of this work was to implement a system that monitors the environmental conditions during the silkworm incubation process. The system was tested in real time.

Data was exported from the RPi3 to a plain .txt file in a Google Drive account and is available here. The data provides date, hour, temperatures measures from sensor one to sensor nine, humidity measures from sensor one to sensor nine, and the sensor light measure. Currently, our monitoring system is still working.

Environmental condition uniformity inside the incubator is fundamental. However, through analysis of data, the generation of microclimates between incubator levels is evident, as shown in Figure 6 for temperature variance and Figure 7 for humidity variance. We provide more graphics in GitHub. This situation may be affect the biological as well as physiological characteristics (i.e., growth, development, productivity, and quality of silk) of the silkworm.

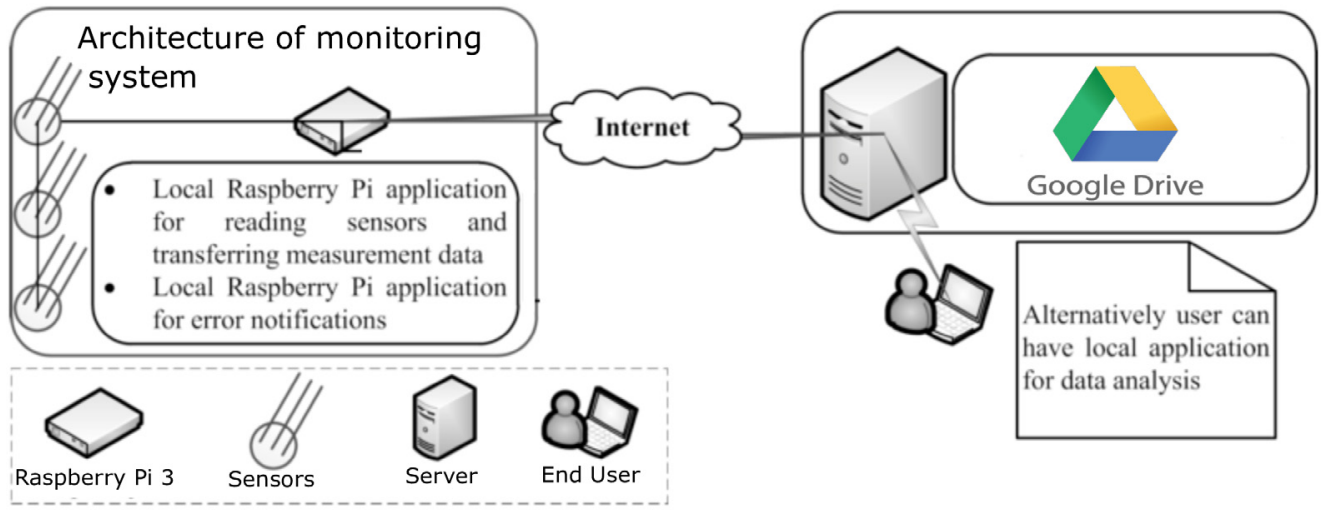

Figure 5. Architecture of the monitoring system. 


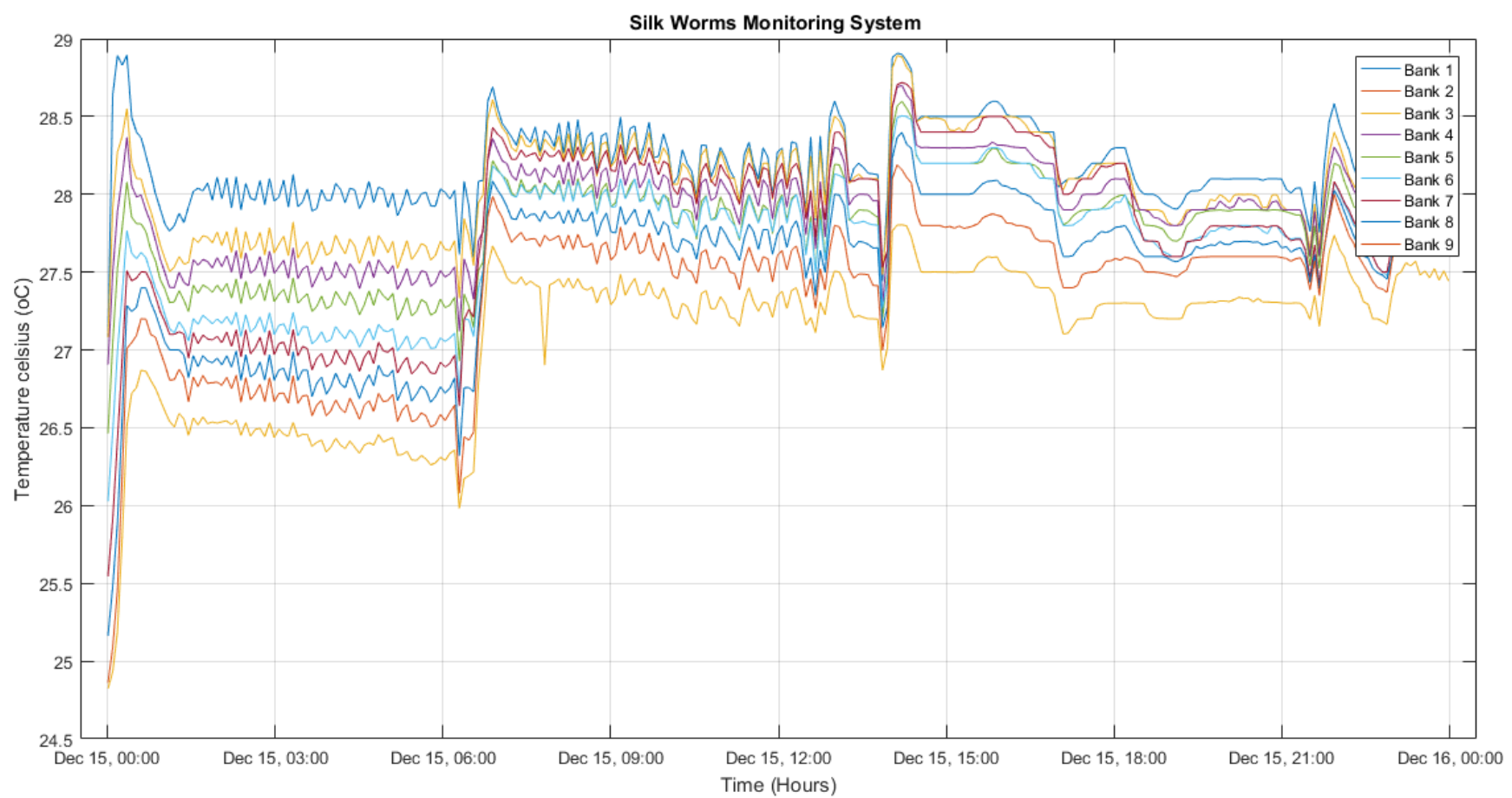

Figure 6. Temperature variance graphic.

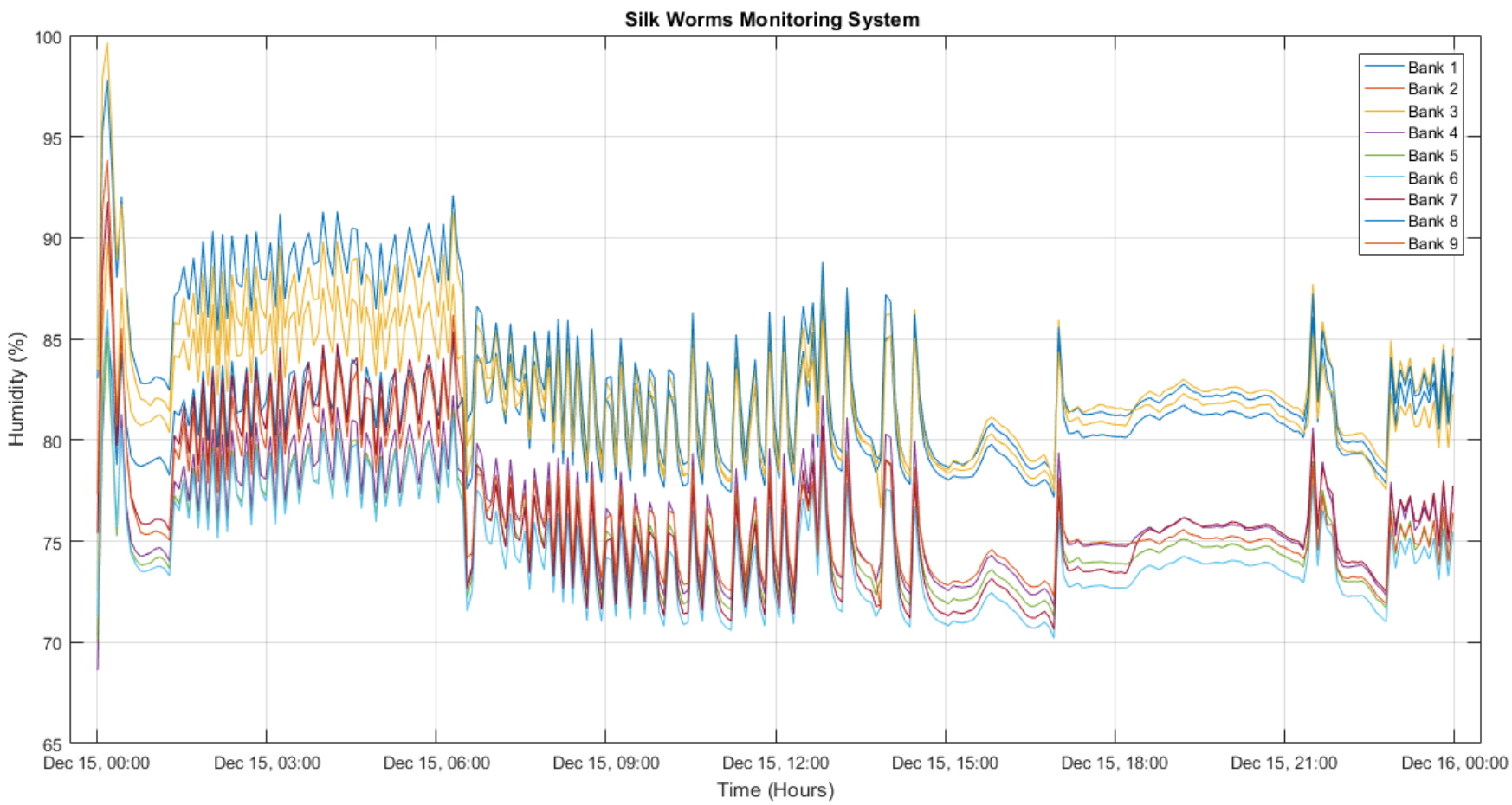

Figure 7. Humidity variance graphic. 


\section{Conclusions}

In this study, we describe a prototype for an environmental monitoring system created with Raspberry Pi. It allows recordings of temperature, humidity, and luminosity values in a silkworm incubator in natural conditions. In this work, we demonstrated the reliability offered by the Raspberry $\mathrm{Pi}$ in providing temperature, humidity and light readings in our field test, which was carried out for many days and in the University of Cauca silkworm incubators.

The present study only addresses one of the possible solutions for registering environmental parameters, which should minimize financial costs and human resources. We believe in the possibility of improving the general aspects of the incubator through the analysis of data provided by this monitoring system, as well as the quality of the breeding process of silkworms.

Our proposed system has low cost and portability quality, which are essential for the recording of environmental conditions. Moreover, it supports useful features like remote data view and data analysis. In the next update of the system, we will implement an alarm system.

The proposed system offers new opportunities for researchers working in similar environments, i.e. those that need monitoring of environmental conditions accurately. The second important goal achieved is in this study is the automatic recording of the environmental conditions (temperature, humidity, and luminosity). This automatic recording is significant for researchers because it improves the analysis process to benefit its research results. Our device is directly programmable, and is based on open source codes, which increases the overall flexibility of the instrument. This feature is rarely present in commercial tools that provide only predetermined functions.

We believe that in the near future, researchers in other fields will be able to use an adapted version of this system.

\section{Data and software availability}

All data collected during this study and the all code for setting up the incubator are available on GitHub: https://github.com/Silkwormincubator/SilkWorm/

Archived source code as at the time of publication: http://doi. org/10.5281/zenodo. $1161294^{13}$

License: Creative Commons Attribution Share-Alike 4.0.

\section{Competing interests}

No competing interests were disclosed.

\section{Grant information}

This research is funded by Colciencias Doctoral scholarship 647-2014 for the PhD in Telematic Engineering at the Universidad del Cauca, Popayán, Colombia. The purchase of the materials was made with resources provided by the National Ph.D. Scholarship for Teachers granted by the Human Talent Training Network Project for Social and Productive Innovation in the Department of Cauca - InnovAcción Cauca.

The funders had no role in study design, data collection and analysis, decision to publish, or preparation of the manuscript.

\section{Acknowledgements}

The authors wish to thank the University of Cauca and the following research groups: the Geology, Ecology and Conservation research group (GECO), Telematic Engineering Group (GIT) and the Integrated Production Systems Research Group (SISINPRO). Also to the projects InnovAccion-Cauca and Technical Development for production of Innovative Organic Silk Products Project, from the General Royalties System, and the Government of Cauca (Colombia).
1. Rahmathulla VK: Management of climatic factors for successful silkworm (Bombyx mori L.) crop and higher silk production: A review. Psyche (New York). 2012; 2012(2012): 12 Publisher Full Text

2. Rao CG, Seshagiri SV, Ramesh C, et al.: Evaluation of genetic potential of the polyvoltine silkworm (Bombyx mori L.) germplasm and identification of parents for breeding programme. J Zheiiang Univ Sci B. 2006; 7(3): 215-20. PubMed Abstract | Publisher Full Text | Free Full Text

3. Wu HI, Sharpe PJ, Wagner TL, et al.: Modeling insects development rates: a literature review and application of biophysical model. Entomol Soc Am. 1984; 77(2): 208-220.

Publisher Full Text

4. De Postgraduados C: Effect of Temperature and Relative Humidity on. 2011; 1(311): 42-53.

5. Dezmirean D, Nagy A, Mărghitaş A: Diapause Storage Temperature Influence on Silkworm Larva Hatching Rate. Analele Universitătii din Oradea, Fascicula: Ecotoxicologie, Zootehnie și Tehnologii de Industrie Alimntară. 2015; XIV B: 341-348. Reference Source

6. Hussain M, Khan SA, Naeem M, et al:: Effect of rearing temperature and humidity on fecundity and fertility of silkworm, Bombyx mori L. (Lepidoptera: Bombycidae). Pak J Zool. 2011; 43(5): 979-985. Reference Source

7. Ruiz-Rosero J, Ramirez-Gonzalez G, Williams JM, et al:: Internet of things: A scientometric review. Symmetry. 2017; 9(12): 301. Publisher Full Text

8. Mesas-Carrascosa FJ, Verdú Santano D, Meroño JE, et al:: Open source hardware to monitor environmental parameters in precision agriculture. Biosyst Eng. 2015; 137: 73-83.

Publisher Full Text

9. Ferdoush S, Li X: Wireless sensor network system design using Raspberry $\mathrm{Pi}$ and Arduino for environmental monitoring applications. Procedia Comput Sci. 2014; 34: 103-110. Publisher Full Text

10. Pasquali V, D'Alessandro G, Gualtieri R, et al:: A new data logger based on Raspberry-Pi for Arctic Notostraca locomotion investigations. Measurement (Lond). 2017; 110: 249-256 Publisher Full Text

11. Pereira RIS, Dupont IM, Carvalho PCM, et al:: IoT embedded linux system based on Raspberry $\mathrm{Pi}$ applied to real-time cloud monitoring of a decentralized photovoltaic plant. Measurement (Lond). 2018; 114: 286-297. Publisher Full Text

12. Vujović V, Maksimović M: Raspberry pi as a sensor web node for home automation. Comput Electr Eng. 2015; 44(Supplement C): 153-171. Publisher Full Text

13. Duque-Torres A, Ruiz-Rosero J, Zambrano-Gonzalez G, et al.: A New Environmental Monitoring System For Silkworm Incubators (Version 2). zenodo. 2018. Data Source 


\section{Open Peer Review}

\section{Current Peer Review Status:}

\section{Version 1}

Reviewer Report 16 September 2021

https://doi.org/10.5256/f1000research.14811.r93139

(C) 2021 Barik L. This is an open access peer review report distributed under the terms of the Creative Commons Attribution License, which permits unrestricted use, distribution, and reproduction in any medium, provided the original work is properly cited. The author(s) is/are employees of the US Government and therefore domestic copyright protection in USA does not apply to this work. The work may be protected under the copyright laws of other jurisdictions when used in those jurisdictions.

\section{LalBihari Barik}

King Abdulaziz University, Rabigh, Saudi Arabia

The research is a new prototype for silkworm incubators that monitors environmental conditions storage of data in the cloud.

The method's description technically sounds as they use different sensors to collect data on temperature, humidity, and luminosity.

There are partial details provided to allow replication of the method development due to the clock speed processor compared to the latest version.

All the source data underlying the results are available to ensure partial reproducibility.

The conclusions are satisfactory as they implement the alarm system in the later phase.

Is the rationale for developing the new method (or application) clearly explained?

Yes

Is the description of the method technically sound?

Yes

Are sufficient details provided to allow replication of the method development and its use by others?

Partly

If any results are presented, are all the source data underlying the results available to ensure full reproducibility? 
Partly

Are the conclusions about the method and its performance adequately supported by the findings presented in the article?

Partly

Competing Interests: No competing interests were disclosed.

Reviewer Expertise: Lalbihari Barik, (Ph.D. Computer Science) has over 20 years of industrial \& educationalexperience in the field of Java, network technologies, AI, IoT, ITS, Big Data, Cloud Computing,Self-Efficacy, and Stock Market analysis. He has worked on various web-driven projects whereexaMAIZE is one of his educational brand products. He honored the "IBM Drona Award 2008",and "Developer Super Star 2011" in the national level software development program organizedby IBM. He serves as a resource person for many workshops in open-source software, processmining, etc. He received research granted projects and published and presented several researchpapers in National and International Journals and books.

I confirm that I have read this submission and believe that I have an appropriate level of expertise to confirm that it is of an acceptable scientific standard.

Reviewer Report 06 April 2018

https://doi.org/10.5256/f1000research.14811.r32803

(c) 2018 Leccese $\mathbf{F}$ et al. This is an open access peer review report distributed under the terms of the Creative Commons Attribution License, which permits unrestricted use, distribution, and reproduction in any medium, provided the original work is properly cited.

\section{Enrico Petritoli}

Department of Science, Roma Tre University, Rome, Italy

Fabio Leccese

Department of Science, Roma Tre University, Rome, Italy

I'm happy to see a work like yours that realizes a "climate chamber" for silkworms. By climate chamber I mean a complex structured monitoring system for some entities useful for the life of the silkworms, and is able to suitably act to control the chamber and able to provide information of the entities on the internet.

I have mixed feelings about the article: from one side the work is extremely clear and describes well all single steps made to realize the system, providing all the information to replicate the system, but from a scientific point of view, it does not seem innovative. The paper could be improved under many point of view as a study of reliability, consideration of the accuracy of the system and from a biological point of view explaining what could happen to animals if something is not fully managed, etc. 
Anyway, considering the effort made to do this system, considering that the application can be considered partially innovative and considering that you talk about preliminary test letting, you imagine that this is a first step of a longer research and I can consider it positive.

The current structure of the paper prevents me giving punctual improvements because, as I said, the paper is well written and important changes are no compatible with the time of the revision. The only thing that I ask is to improve your bibliography, is insufficient for an International scientific journal.

I'll suggest many papers that you could insert in your, I admit, some of them are mine because I have a good experience in this field, but you are completely free to decide to insert them or not; anyway I wish that you expand your bibliography.

\section{References}

1. Pasquali V, D'Alessandro G, Gualtieri R, Leccese F: A new data logger based on Raspberry-Pi for Arctic Notostraca locomotion investigations. Measurement. 2017; 110: 249-256 Publisher Full Text 2. Leccese F, Cagnetti M, Di Pasquale S, Giarnetti S, et al.: A New Power Quality Instrument Based on Raspberry-Pi. Electronics. 2016; 5 (4). Publisher Full Text

3. Pasquali V: Experimental in field reliability test for data logger based on Raspberry-Pi for extreme scenarios: A first step versus aerospace applications. 3rd IEEE International Workshop on Metrology for Aerospace, MetroAeroSpace 2016. 2016. 365-370

4. Pasquali V, Gualtieri R, D'Alessandro G, Granberg M, et al.: Monitoring and Analyzing of Circadian and Ultradian Locomotor Activity Based on Raspberry-Pi. Electronics. 2016; 5 (4). Publisher Full Text

5. Leccese $F$, Cagnetti $M$, Calogero A, Trinca D, et al.: A new acquisition and imaging system for environmental measurements: an experience on the Italian cultural heritage.Sensors (Basel). 2014; 14 (5): 9290-312 PubMed Abstract | Publisher Full Text

6. Leccese F, Cagnetti M, Trinca D: A smart city application: a fully controlled street lighting isle based on Raspberry-Pi card, a ZigBee sensor network and WiMAX.Sensors (Basel). 2014; 14 (12): 24408-24 PubMed Abstract | Publisher Full Text

7. Kölling M: Educational Programming on the Raspberry Pi. Electronics. 2016; 5 (4). Publisher Full Text

8. Basford P, Bragg G, Hare J, Jewell M, et al.: Erica the Rhino: A Case Study in Using Raspberry Pi Single Board Computers for Interactive Art. Electronics. 2016; 5 (4). Publisher Full Text

9. Reck R, Sreenivas R: Developing an Affordable and Portable Control Systems Laboratory Kit with a Raspberry Pi. Electronics. 2016; 5 (4). Publisher Full Text

10. Schlobohm J, Pösch A, Reithmeier E: A Raspberry Pi Based Portable Endoscopic 3D Measurement System. Electronics. 2016; 5 (4). Publisher Full Text

11. Calvo I, Gil-García J, Recio I, López A, et al.: Building IoT Applications with Raspberry Pi and Low Power IQRF Communication Modules. Electronics. 2016; 5 (4). Publisher Full Text

12. Zhong X, Liang Y: Raspberry Pi: An Effective Vehicle in Teaching the Internet of Things in

Computer Science and Engineering. Electronics. 2016; 5 (4). Publisher Full Text

13. Jennehag U, Forsstrom S, Fiordigigli F: Low Delay Video Streaming on the Internet of Things Using Raspberry Pi. Electronics. 2016; 5 (4). Publisher Full Text

14. Ambrož M: Raspberry Pi as a low-cost data acquisition system for human powered vehicles. Measurement. 2017; 100: 7-18 Publisher Full Text

\section{Is the rationale for developing the new method (or application) clearly explained?}


Yes

Is the description of the method technically sound?

Yes

Are sufficient details provided to allow replication of the method development and its use by others?

Yes

If any results are presented, are all the source data underlying the results available to ensure full reproducibility?

Yes

Are the conclusions about the method and its performance adequately supported by the findings presented in the article?

Yes

Competing Interests: No competing interests were disclosed.

Reviewer Expertise: Raspberry-Pi, Public Lighting, Measurement, ADC Conversion, Energy Efficiency, Wireless Sensor Network

We confirm that we have read this submission and believe that we have an appropriate level of expertise to confirm that it is of an acceptable scientific standard, however we have significant reservations, as outlined above.

The benefits of publishing with F1000Research:

- Your article is published within days, with no editorial bias

- You can publish traditional articles, null/negative results, case reports, data notes and more

- The peer review process is transparent and collaborative

- Your article is indexed in PubMed after passing peer review

- Dedicated customer support at every stage

For pre-submission enquiries, contact research@f1000.com 